\title{
Associations between Genetically Predicted Circulating Protein Concentrations and Endometrial Cancer Risk
}

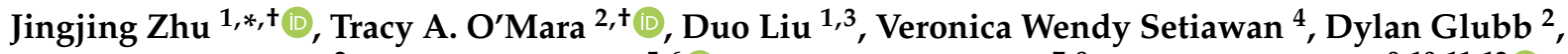 \\ Amanda B. Spurdle ${ }^{2}$, Peter A. Fasching ${ }^{5,6} \mathbb{D}^{\text {, Diether Lambrechts }}{ }^{7,8}$, Daniel Buchanan $9,10,11,12 \mathbb{}$, \\ Pik Fang Kho ${ }^{2}$, Linda S. Cook ${ }^{13}$, Christine Friedenreich ${ }^{14}{ }^{\mathbb{D}}$, James V. Lacey ${ }^{15}$, Chu Chen ${ }^{16}$, \\ Nicolas Wentzensen ${ }^{17}$, Immaculata De Vivo ${ }^{18,19}$, Yan Sun ${ }^{20}$, Jirong Long ${ }^{20}$, Mengmeng Du ${ }^{21}$, \\ Xiao-Ou Shu ${ }^{20}$, Wei Zheng ${ }^{20}$, Lang $\mathrm{Wu}^{1, \ddagger}$ and Herbert $\mathrm{Yu}{ }^{1, \ddagger}$
}

Citation: Zhu, J.; O'Mara, T.A.; Liu, D.; Setiawan, V.W.; Glubb, D.; Spurdle, A.B.; Fasching, P.A.; Lambrechts, D.; Buchanan, D.; Kho, P.F.; et al. Associations between Genetically Predicted Circulating Protein Concentrations and Endometrial Cancer Risk. Cancers 2021, 13, 2088

https://doi.org/10.3390/

cancers 13092088

Academic Editor: Álvaro González

Received: 8 March 2021

Accepted: 21 April 2021

Published: 26 April 2021

Publisher's Note: MDPI stays neutral with regard to jurisdictional claims in published maps and institutional affiliations.

Copyright: (c) 2021 by the authors. Licensee MDPI, Basel, Switzerland. This article is an open access article distributed under the terms and conditions of the Creative Commons Attribution (CC BY) license (https:/ / creativecommons.org/licenses/by/ $4.0 /)$.
1 Population Sciences in the Pacific Program, Cancer Epidemiology Division, University of Hawaii Cancer Center, University of Hawaii at Manoa, Honolulu, HI 96813, USA; liuduo95@126.com (D.L.);

Lwu@cc.hawaii.edu (L.W.); hyu@cc.hawaii.edu (H.Y.)

2 Department of Genetics and Computational Biology, QIMR Berghofer Medical Research Institute, Brisbane, QLD 4006, Australia; Tracy.OMara@qimrberghofer.edu.au (T.A.O.);

Dylan.Glubb@qimrberghofer.edu.au (D.G.); Amanda.Spurdle@qimrberghofer.edu.au (A.B.S.); PikFang.Kho@qimrberghofer.edu.au (P.F.K.)

3 Department of Pharmacy, Harbin Medical University Cancer Hospital, Harbin 150086, China

4 Department of Preventive Medicine, Keck School of Medicine and Norris Comprehensive Cancer Center, University of Southern California, Los Angeles, CA 90089, USA; vsetiawa@usc.edu

5 Department of Gynecology and Obstetrics, Comprehensive Cancer Center ER-EMN, University Hospital Erlangen, Friedrich-Alexander-University Erlangen-Nuremberg, 91054 Erlangen, Germany; peter.fasching@fau.de

6 Department of Medicine Division of Hematology and Oncology, David Geffen School of Medicine, University of California, Los Angeles, CA 90095, USA

7 Laboratory for Translational Genetics, Department of Human Genetics, University of Leuven, 3000 Leuven, Belgium; diether.lambrechts@kuleuven.vib.be

8 VIB, VIB Center for Cancer Biology, 3000 Leuven, Belgium

9 Department of Clinical Pathology, The University of Melbourne, Melbourne, VIC 3010, Australia; daniel.buchanan@unimelb.edu.au

10 Centre for Epidemiology and Biostatistics, Melbourne School of Population and Global Health, The University of Melbourne, Melbourne, VIC 3010, Australia

11 Genomic Medicine and Family Cancer Clinic, Royal Melbourne Hospital, Parkville, VIC 3052, Australia

12 Victorian Comprehensive Cancer Centre, University of Melbourne Centre for Cancer Research, Parkville, VIC 3000, Australia

13 Epidemiology, Biostatistics and Preventive Medicine, Department of Internal Medicine, University of New Mexico, Albuquerque, NM 87131,USA; lcook@salud.unm.edu

14 Department of Cancer Epidemiology and Prevention Research, Alberta Health Services, Calgary, AB T2S 3C3, Canada; Christine.Friedenreich@albertahealthservices.ca

15 Department of Computational and Quantitative Medicine, City of Hope, Duarte, CA 91010, USA; jlacey@coh.org

16 Epidemiology Program, Fred Hutchinson Cancer Research Center, Seattle, WA 98109, USA; cchen@fhcrc.org

17 Division of Cancer Epidemiology and Genetics, National Cancer Institute, Bethesda, MD 20892, USA; wentzenn@mail.nih.gov

18 Department of Epidemiology, Harvard T.H. Chan School of Public Health, Boston, MA 02115, USA; devivo@channing.harvard.edu

19 Department of Medicine, Harvard Medical School, Channing Division of Network Medicine, Brigham and Women's Hospital, Boston, MA 02115, USA

20 Vanderbilt Epidemiology Center, Vanderbilt-Ingram Cancer Center, Department of Medicine, Division of Epidemiology, Vanderbilt University School of Medicine, Nashville, TN 37232, USA; yan.sun@vanderbilt.edu (Y.S.); jirong.long@vumc.org (J.L.); xiao-ou.shu@Vanderbilt.Edu (X.-O.S.); wei.zheng@vumc.org (W.Z.)

21 Department of Epidemiology and Biostatistics, Memorial Sloan Kettering Cancer Center, New York, NY 10065, USA; dumeng@mskcc.org

* Correspondence: jzhu@cc.hawaii.edu

+ These authors contributed equally to this work and are co-first authors.

$\ddagger$ These authors jointly supervised this work and are co-senior authors. 
Simple Summary: Endometrial cancer is the leading female reproductive tract cancer in developed countries. Discovering new biomarkers is critical for understanding the etiology this cancer and identifying women with a higher risk of this cancer from the general population. Several blood protein biomarkers have been linked to endometrial cancer in previous studies, but these studies have assessed only a limited number of biomarkers usually among a small number of participants. The current study aimed at identifying novel circulating protein biomarkers of endometrial cancer by using the largest available dataset to date. Our finding suggested nine proteins to be associated with endometrial cancer risk, and five of the identified associations showed suggestive associations with risk of non-endometrioid EC, a much more lethal subtype. If validated by additional studies, our findings may contribute to understanding the pathogenesis of endometrial tumor development and facilitating the risk assessment of endometrial cancer.

Abstract: Endometrial cancer (EC) is the leading female reproductive tract malignancy in developed countries. Currently, genome-wide association studies (GWAS) have identified 17 risk loci for EC. To identify novel EC-associated proteins, we used previously reported protein quantitative trait loci for 1434 plasma proteins as instruments to evaluate associations between genetically predicted circulating protein concentrations and EC risk. We studied 12,906 cases and 108,979 controls of European descent included in the Endometrial Cancer Association Consortium, the Epidemiology of Endometrial Cancer Consortium, and the UK Biobank. We observed associations between genetically predicted concentrations of nine proteins and EC risk at a false discovery rate of $<0.05$ ( $p$-values range from $1.14 \times 10^{-10}$ to $3.04 \times 10^{-4}$ ). Except for vascular cell adhesion protein 1 , all other identified proteins were independent from known EC risk variants identified in EC GWAS. The respective odds ratios (95\% confidence intervals) per one standard deviation increase in genetically predicted circulating protein concentrations were $1.21(1.13,1.30)$ for DNA repair protein RAD51 homolog $4,1.27(1.14,1.42)$ for desmoglein-2, $1.14(1.07,1.22)$ for MHC class I polypeptide-related sequence B, $1.05(1.02,1.08)$ for histo-blood group ABO system transferase, $0.77(0.68,0.89)$ for intestinal-type alkaline phosphatase, $0.82(0.74,0.91)$ for carbohydrate sulfotransferase $15,1.07(1.03,1.11)$ for Dglucuronyl C5-epimerase, and $1.07(1.03,1.10)$ for CD209 antigen. In conclusion, we identified nine potential EC-associated proteins. If validated by additional studies, our findings may contribute to understanding the pathogenesis of endometrial tumor development and identifying women at high risk of EC along with other EC risk factors and biomarkers.

Keywords: genetic instrument; protein biomarker; endometrial cancer; risk

\section{Introduction}

Endometrial cancer (EC) is a leading gynecological malignancy in developed countries [1]. It is also one of the few cancer types with a rapidly increasing incidence and mortality as the rate of obesity continues to grow worldwide [2]. Hence, it is reasonable to predict that EC will become an important public health challenge in the coming years. There is an urgent need to reduce the disease burden by enhancing the understanding of the EC etiology and distinguishing high-risk women from the general population.

Traditionally, EC is classified into two main histological subtypes. Endometrioid adenocarcinomas represent more than $70 \%$ of cases. Tumors of this type are usually lowgrade and diagnosed at an early stage. In contrast, the less common non-endometrioid tumors are typically more aggressive and often diagnosed at an advanced stage. Although the prognosis of EC remains generally good, it worsens dramatically when diagnosed at an advanced stage, with a median survival time of less than 12 months $[1,3]$. To improve the treatment efficacy and survival outcomes of this disease, it is critical to detect EC at the earliest possible stage. The discovery of potential non-invasive biomarkers would thus be especially important for identifying women with a high risk of EC [4,5]. Although many protein candidates in blood or vagina samples have been reported as possible 
biomarkers, most of these studies have only assessed a limited number of candidates or yielded inconsistent results $[4,6,7]$. For instance, several studies found associations of serum level of cancer antigen 15-3 and serum amyloid A with an increased risk of EC, while others showed inverse or null associations [8-14]. These studies using a conventional epidemiological design are potentially subject to selection biases, residual confounding, or reverse causality. Furthermore, they were often limited by a small sample size and a limited number of protein candidates available for evaluation.

To identify novel protein biomarkers for EC, here, we used protein quantitative trait loci (pQTL) from a recently published genome-wide association study (GWAS) as genetic instruments to investigate the associations between genetically predicted protein concentrations and EC risk. Due to the independent assortment of alleles transmitted from parents to offspring during gamete formation, such a design can potentially address several limitations of conventional epidemiological studies [15]. We leveraged comprehensive data of 12,906 EC cases and 108,979 controls of European ancestry generated in the Endometrial Cancer Association Consortium (ECAC), the Epidemiology of Endometrial Cancer Consortium (E2C2), and the UK Biobank.

\section{Methods}

After an extensive literature search and rigorous evaluation, we identified a comprehensive study analyzing associations between genetic variants and blood-based protein concentrations and used pQTLs identified in this study as the instruments for our analyses [16]. By analyzing data on 3562 healthy European descendants with adjustment for age, sex, duration between blood draw and processing, and the first three principal components (PCs), this study identified 764 genomic loci that were associated $\left(p<1.5 \times 10^{-11}\right)$ with expression levels of 1478 proteins, involving a total of 1927 associations [16]. Instrumental variables were created based on these PQTLs to examine the associations between genetically predicted protein concentrations and EC risk. When there were more than one variant located at the same chromosome associated with a single protein, we only retained single nucleotide polymorphisms (SNPs) that were independent of each other, as defined by $R^{2}<0.1$ (based on 1000 Genomes Project Phase 3 version 5 data focusing on European populations).

To understand the associations between genetically predicted protein levels and EC risk, we used summary statistics from the largest GWAS meta-analysis previously conducted to evaluate the association between genetic variants and the risk of developing EC [17]. In brief, 12,906 EC cases and 108979 controls of European descent from 17 studies as part of the ECAC, E2C2, and the UK Biobank were included. Stratified analyses were also performed by histologic subtype including endometrioid $(n=8758)$ and non-endometrioid carcinomas $(n=1230)$. These participants were genotyped via various platforms. Among them, 4710 EC cases were genotyped using the OncoArray chip, and were country-matched to 19,438 controls who were genotyped in the same way from the Breast Cancer Association Consortium [17]. The 2381 cases and 13,675 controls from the iCOGs studies were genotyped using the Illumina Infinium iSelect array. Regarding participants from E2C2, the 2271 cases and 2219 controls in the United States were genotyped using the Illumina Human OmniExpress array, and 424 cases and 558 controls from Poland were genotyped using the Illumina Human 660W array. Data from the UK biobank, including 636 EC cases and 62853 controls, were genotyped using the Affymetrix UK BiLEVE Axiom array and Affymetrix UK Biobank Axiom array. The 288 cases and 1440 controls identified from the Women's Health Initiative were genotyped using five different arrays (Illumina Human Omni1-Quad v1-0 B; Illumina 610; Human OmniExpressExome-8v1-1-A; Axiom Genome-Wide Human CEU; Human OmniExpress-8v1_B). Information on genotyping and imputation methods for the samples from other published GWAS studies can be found in the original GWAS paper [17]. Risk estimates for the SNP-EC associations estimated in each study with adjustment for PCs were meta-analyzed by inverse variance weighted (IVW) 
fixed-effects methods [18]. All participating studies were approved by their appropriate ethics committees with written and informed consent from all participants.

Based on the summary estimates from the pQTL study and the EC GWAS metaanalysis mentioned above, we assessed the associations between genetically predicted circulating protein concentrations and EC risk by using the IVW method $[19,20]$. Briefly, the estimated beta coefficient and corresponding standard error (SE) of the association between each protein and EC risk were calculated using the formula of $\sum_{i} \beta_{i, G X} * \beta_{i, G Y} *$ $\sigma_{i, G Y}^{-2} /\left(\sum_{i} \beta_{i, G X}^{2} * \sigma_{i, G Y}^{-2}\right)$ and $1 /\left(\sum_{i} \beta_{i, G X}^{2} * \sigma_{i, G Y}^{-2}\right)^{0.5}$, respectively, where $\beta_{i, G X}$ represents the beta coefficient for the association between each SNP and protein level adopted from the PQTL study; $\beta_{i, G Y}$ and $\sigma_{i, G Y}$ represent the estimated beta coefficient and SE of the association between each individual SNP and EC risk in the latest GWAS [20]. Odds ratios (ORs) and confidence intervals (CIs) were further calculated by exponentiating the beta coefficients. Analyses were also carried out separately for endometrioid and nonendometrioid carcinomas, considering the possible etiological heterogeneity. Statistical significance was determined by a Benjamini-Hochberg false discovery rate (FDR) of $<0.05$. For proteins showing an association, conditional and joint multiple-SNP analysis (COJO) conditional analysis was used to examine the robustness of the identified association after conditioning on known GWAS-identified EC risk variants. The ingenuity pathway analysis (IPA) was conducted to visualize the canonical pathways, relevant diseases, biological functions, and networks enriched by genes encoding the proteins associated with EC risk in our PQTL analysis [21].

\section{Results}

We assessed the associations between genetically predicted circulating levels of 1434 proteins and EC risk using pQTLs as instrument variables. Among the examined proteins, nine showed associations with EC risk at a FDR of $<0.05$, and five satisfied Bonferroni criterion $(0.05 / 1434)$. Positive associations were observed for six of the identified proteins, including DNA repair protein RAD51 homolog 4 (RA51D), desmoglein-2, MHC class I polypeptide-related sequence $\mathrm{B}(\mathrm{MICB})$, histo-blood group $\mathrm{ABO}$ system transferase (BGAT), D-glucuronyl C5-epimerase (GLCE) and CD209 antigen (DC-SIGN), with ORs ranging from 1.05 to 1.27 (Table 1). We observed negative associations for three proteins: vascular cell adhesion protein 1 (VCAM-1), intestinal-type alkaline phosphatase, and carbohydrate sulfotransferase 15 (ST4S6), with ORs ranging from 0.60 to 0.82 (Table 1). The instruments used for VCAM-1, MICB, BGAT, intestinal-type alkaline phosphatase, and ST4S6 only had one SNP; whereas two SNPs were used as the instrument to predict the circulating level of RA51D, desmoglein-2, GLCE, and DC-SIGN. Except for VCAM-1 in which the instrument variant (rs3184504) was previously reported as an EC risk SNP, the observed associations for all other identified proteins were independent from known EC risk SNPs from the published GWAS [17]. COJO conditional analysis showed that associations between those eight predicted proteins and EC risk generally remained the same after conditioning on known EC risk variants identified in previous GWAS (Table 1).

Subgroup analyses by histologic subtype of EC suggested that most of the identified associations in the combined analysis remained the same for either endometrioid or nonendometrioid histotype, although many of the associations failed to reach multi-testingadjusted statistical significance due to reduced sample sizes. Of the nine proteins identified in our main analysis, the uncorrected $p$-value ranged from $3.16 \times 10^{-2}$ (DC-SIGN) to $5.78 \times 10^{-9}(\mathrm{VCAM}-1)$ for their associations with endometrioid EC risk. Regarding the rare and aggressive non-endometrioid EC, the uncorrected $p$-values were less than 0.02 for VCAM-1, BGAT, alkaline phosphatase intestine, ST4S6 and DC-SIGN. The directions of the associations between these five proteins and EC risk were consistent across the combined and subgroup analyses (Table 2). 
Table 1. Associations between genetically predicted protein concentrations and endometrial cancer risk.

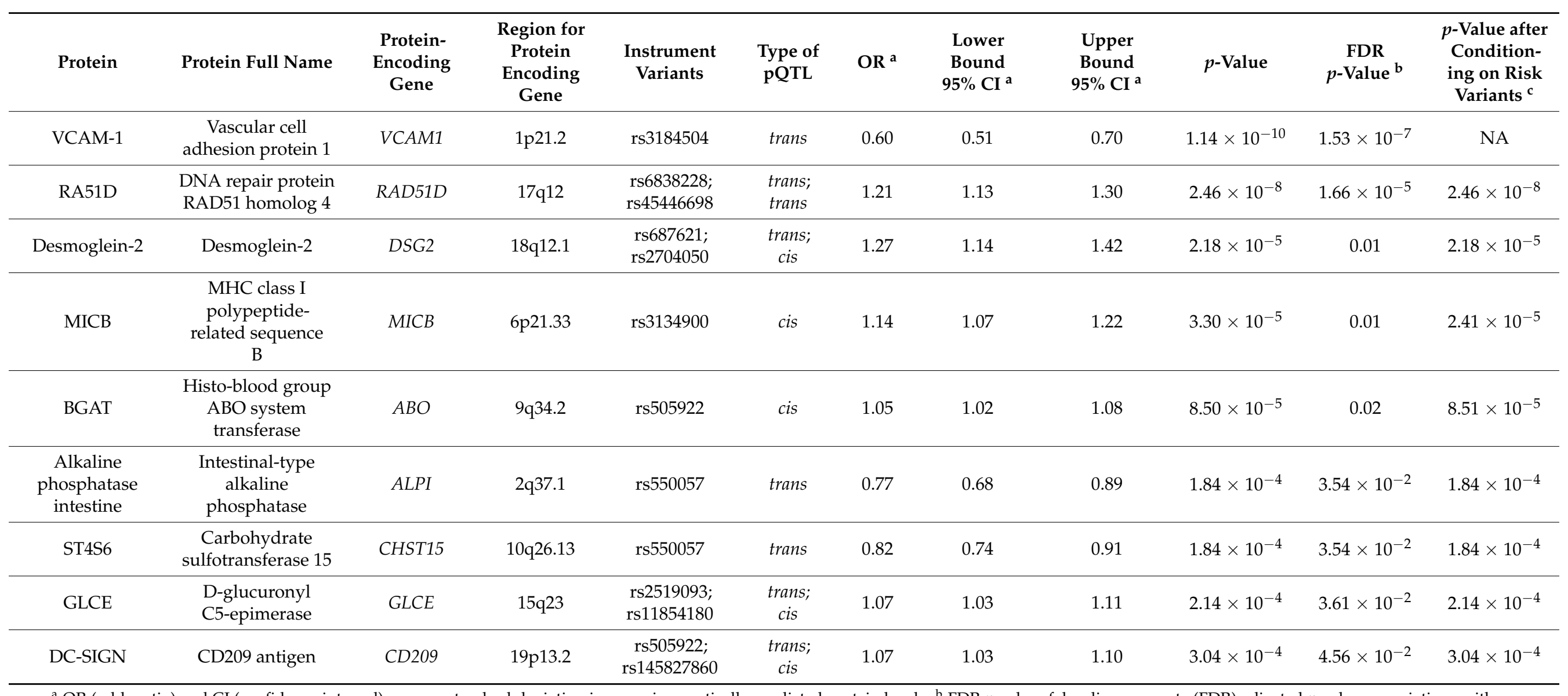

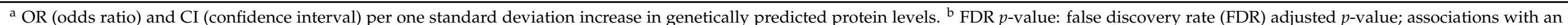

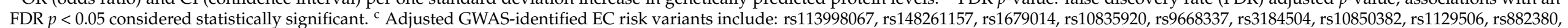
rs1740828, rs2747716, rs35286446, rs4733613, rs139584729, rs7981863, rs2498796, rs937213, rs17601876, rs11263761. 
Table 2. Associations between genetically predicted protein concentrations and endometrial cancer risk by subtypes of endometrial cancer (endometrioid and non-endometrioid).

\begin{tabular}{|c|c|c|c|c|c|c|c|c|}
\hline \multirow{2}{*}{ Protein } & \multicolumn{4}{|c|}{$\begin{array}{c}\text { Endometrioid } \\
\text { (8758 Cases/46 126 Controls) }\end{array}$} & \multicolumn{4}{|c|}{$\begin{array}{c}\text { Non-Endometrioid } \\
\text { (1230 Cases/35 } 447 \text { Controls) }\end{array}$} \\
\hline & $\mathrm{OR}^{\mathrm{a}}$ & $\begin{array}{l}\text { Lower Bound } \\
\quad 95 \% \mathrm{CI}^{\mathrm{a}}\end{array}$ & $\begin{array}{l}\text { Upper Bound } \\
95 \% \mathrm{CI}^{\mathrm{a}}\end{array}$ & $p$-Value & $\mathrm{OR}^{\mathrm{a}}$ & $\begin{array}{l}\text { Lower Bound } \\
\quad 95 \% \mathrm{CI}^{\mathrm{a}}\end{array}$ & $\begin{array}{l}\text { Upper Bound } \\
95 \% \mathrm{CI}^{\mathrm{a}}\end{array}$ & $p$-Value \\
\hline VCAM-1 & 0.58 & 0.48 & 0.69 & $5.78 \times 10^{-9}$ & 0.58 & 0.37 & 0.91 & $1.89 \times 10^{-2}$ \\
\hline RA51D & 1.19 & 1.10 & 1.30 & $1.87 \times 10^{-5}$ & $\mathrm{NA}^{\mathrm{b}}$ & $\mathrm{NA}^{\mathrm{b}}$ & $\mathrm{NA}^{\mathrm{b}}$ & $\mathrm{NA}^{\mathrm{b}}$ \\
\hline Desmoglein-2 & 1.21 & 1.06 & 1.38 & $4.09 \times 10^{-3}$ & 1.35 & 0.98 & 1.85 & $6.84 \times 10^{-2}$ \\
\hline MICB & 1.15 & 1.07 & 1.24 & $2.96 \times 10^{-4}$ & 1.04 & 0.86 & 1.24 & 0.70 \\
\hline BGAT & 1.04 & 1.01 & 1.07 & $1.11 \times 10^{-2}$ & 1.09 & 1.01 & 1.16 & $1.82 \times 10^{-2}$ \\
\hline $\begin{array}{l}\text { Alkaline } \\
\text { phosphatase } \\
\text { intestine }\end{array}$ & 0.84 & 0.71 & 0.98 & $2.46 \times 10^{-2}$ & 0.61 & 0.42 & 0.90 & $1.14 \times 10^{-2}$ \\
\hline ST4S6 & 0.87 & 0.77 & 0.98 & $2.46 \times 10^{-2}$ & 0.68 & 0.51 & 0.92 & $1.14 \times 10^{-2}$ \\
\hline GLCE & 1.07 & 1.02 & 1.12 & $2.14 \times 10^{-3}$ & 0.99 & 0.89 & 1.09 & 0.78 \\
\hline DC-SIGN & 1.05 & 1.00 & 1.09 & $3.16 \times 10^{-2}$ & 1.13 & 1.02 & 1.25 & $1.68 \times 10^{-2}$ \\
\hline
\end{tabular}

${ }^{\mathrm{a}} \mathrm{OR}$ (odds ratio) and CI (confidence interval) per one standard deviation increase in genetically predicted protein levels. ${ }^{\mathrm{b}}$ NAs were due to the unavailability of the GWAS result for the instrument SNP rs45446698.

Pathway analysis by IPA suggested enrichment in several oncogenic pathways for the genes encoding the proteins identified in our study. The top canonical pathways involved those of heparan sulfate biosynthesis at both late $\left(p\right.$-value $\left.=3.41 \times 10^{-4}\right)$ and early stages $\left(p\right.$-value $\left.=4.12 \times 10^{-4}\right)$ as well as crosstalk between dendritic cells and natural killer cells $\left(p\right.$-value $\left.=5.36 \times 10^{-4}\right)($ Table 3$)$.

Table 3. Canonical pathways, diseases, bio functions, and networks associated with the genes encoding identified endometrial cancer risk-associated proteins ${ }^{\mathrm{a}}$.

\begin{tabular}{|c|c|c|c|c|c|}
\hline \multicolumn{3}{|c|}{ Top Canonical Pathways } & \multirow[t]{2}{*}{$\begin{array}{l}\text { Top Diseases } \\
\text { and Disorders }\end{array}$} & \multirow{2}{*}{$\begin{array}{c}\text { Molecular and } \\
\text { Cellular } \\
\text { Functions }\end{array}$} & \multirow[t]{2}{*}{ Top Networks } \\
\hline & $p$-Value & $\begin{array}{c}\text { Involved } \\
\text { Molecules }\end{array}$ & & & \\
\hline $\begin{array}{c}\text { Heparan Sulfate } \\
\text { Biosynthesis (Late Stages); } \\
\text { Heparan Sulfate } \\
\text { Biosynthesis; } \\
\text { Crosstalk between } \\
\text { Dendritic Cells and } \\
\text { Natural Killer Cells; } \\
\text { Dermatan Sulfate } \\
\text { Biosynthesis (Late Stages); } \\
\text { Chondroitin Sulfate } \\
\text { Biosynthesis (Late Stages); }\end{array}$ & $\begin{array}{l}3.41 \times 10^{-4} \\
4.12 \times 10^{-4} \\
5.36 \times 10^{-4}\end{array}$ & $\begin{array}{l}\text { CHST15, GLCE } \\
\text { CHST15, GLCE }\end{array}$ & $\begin{array}{c}\text { Infectious } \\
\text { diseases; } \\
\text { cancer; } \\
\text { cardiovascular } \\
\text { disease; } \\
\text { connective tissue } \\
\text { disorders; } \\
\text { hereditary } \\
\text { disorder. }\end{array}$ & $\begin{array}{l}\text { Cell-to-cell } \\
\text { signaling and } \\
\text { interaction; } \\
\text { cellular movement; } \\
\text { cellular assembly } \\
\text { and organization; } \\
\text { carbohydrate } \\
\text { metabolism; } \\
\text { cell morphology. }\end{array}$ & $\begin{array}{c}\text { Cell-to-cell } \\
\text { signaling and } \\
\text { interaction, } \\
\text { cancer, } \\
\text { connective tissue } \\
\text { disorders. }\end{array}$ \\
\hline
\end{tabular}

a Genes involved in the pathway analysis include VCAM1, RAD51D, DSG2, MICB, ABO, ALPI, CHST15, GLCE, and CD209.

\section{Discussion}

To our knowledge, this is the first study to comprehensively examine the associations between genetically predicted circulating protein concentrations and EC risk among European descendants using data from the largest GWAS conducted by international consortia. Among the 1434 proteins investigated, we identified nine EC-associated proteins after FDR correction, including eight independent from previously identified EC risk variants. Similar findings were observed for endometrioid EC alone. Five of the proteins also showed suggestive associations with the risk of non-endometrioid EC, a much more lethal subtype [22]. If validated in additional studies, our findings add new knowledge to the 
etiology of endometrial tumorigenesis, and yield a list of candidate protein biomarkers for EC risk assessment.

Previous studies have reported a number of blood-based EC protein biomarker candidates such as DKK-1, DJ-1, HE4, CA125, GDF-15, SPAG9, YKL-40, IL-31 and IL-33 [4,6,23]. Unfortunately, there was no corresponding pQTL available as instruments for HE4, CA125, SPAG9 and IL-33. For the other biomarker candidates, we did not observe associations in the current study: DKK-1 (OR = 0.96, 95\% CI: 0.87-1.07; $p$-value $=0.44), \mathrm{DJ}-1(\mathrm{OR}=0.94,95 \%$ CI: 0.87-1.03; $p$-value = 0.17), GDF-15 (OR = 0.98, 95\% CI: 0.93-1.05; $p$-value $=0.59)$, YKL-40 $(\mathrm{OR}=1.00,95 \% \mathrm{CI}: 0.97-1.03 ; p$-value $=0.99)$ and IL-31 $(\mathrm{OR}=0.95,95 \%$ CI: 0.89-1.02; $p$-value $=0.17)$. Explanations for our failure to replicate the associations for DKK-1, DJ-1, GDF-15, YKL-40 and IL-31 might include either the weakness of their corresponding pQTLs used as instruments in our study or false-positive findings due to common biases in conventional observational studies. For example, obesity, the most important risk factor for EC, is also suggested to be associated with measured levels of GDF-15 and YKL-40 [24-26]. Therefore, the reported associations of these proteins with EC risk in previous observational studies could be confounded by obesity due to imperfect adjustment in their analyses [27].

The instrument SNP for VCAM-1 protein, rs3184504, was previously identified as an EC-risk variant and had a trans effect on the protein expression. SH2B3 is a likely regulatory target at this risk region, as evidenced from our previous work using chromatin capture methods in endometrial cell lines [28]. SH2B3 is known to downregulate VCAM-1, which could perhaps be one of the potential mechanisms by which this association is occurring [29]. However, given the pleiotropic nature of SH2B3, we cannot preclude other possible mechanisms for the observed association (e.g., immune and inflammatory signaling pathways) [30]. In the current study, we identified eight EC-associated proteins that are independent of previously identified EC risk variants. Some of them have been reported to play an essential role in endometrial tumorigenesis. Polymorphisms of the gene encoding RA51D have been identified to be associated with EC risk in population-based studies [31,32]. The RA51D is a core protein involved in the homologous recombination and repair of double strand breaks in DNA molecules, which is viewed as the most detrimental DNA damage that can trigger EC development [33]. With regard to protein BGAT, an earlier study found that blood group-related antigens were expressed differently between normal and neoplastic endometria [34]. However, observational studies investigating the association between different $\mathrm{ABO}$ blood types and EC risk yielded inconsistent findings in different populations [35-37]. Not much is known about the remaining proteins we identified. Future studies are warranted to further elucidate the involvement of the proteins we found in endometrial carcinogenesis.

The strengths of our study include the use of the largest GWAS in maximizing the statistical power of our study. Additionally, our study design of using genetic instruments could substantially reduce common biases embedded in traditional observational studies. Nevertheless, we also have to acknowledge several limitations in the current study. First, our findings may be influenced by potential pleiotropic effects. For instance, rs550057, which served as the instrument SNP for both alkaline phosphatase intestine and ST4S6, is also in some linkage disequilibrium with several instrument SNPs of other identified proteins. Thus, whether the identified associations in our study were attributable to correlations between protein concentrations needs further investigation. Similarly, rs45446698, which was one of the instrument variants for protein RA51D, has been linked to urinary metabolite levels in chronic kidney disease, offspring birth weight, heel bone mineral density and height [38-41]. Nevertheless, none of these traits have shown a strong independent relationship with EC risk. Second, given that the observed associations for the identified proteins were only based on the genetically regulated components in our study, the utility of their measured circulating protein concentrations for EC risk assessment needs to be further verified and then validated. Third, relying on previously identified pQTLs as instrument variables, we were only able to evaluate protein candidates with at least one existing pQTL identified. Due to this limitation, we were not able to compare 
our findings to some of the previously reported EC protein biomarker candidates. We anticipate that additional protein biomarkers will be uncovered with the identification of new pQTLs in future studies, as well as in a study of using more thorough methods to predict protein concentrations using a combination of multiple genetic variants, which is expected to further increase study power. Moreover, we failed to replicate the associations for several previously reported possible EC protein biomarkers, which might be explained by either the weakness of the corresponding pQTLs used as instruments in our study or distinct study designs between our study and the previous studies. In addition, given that the associations identified in our study have moderate effect sizes and we were unable to provide detailed functional validation at this moment, our findings may not have immediate potential for translating into clinical use based on the current results. On the other hand, our findings should provide additional insights into the etiology of endometrial cancer. The identified associations provide a basis for future investigation of directly measured levels of the nine proteins in risk assessment of endometrial cancer. It is possible that although the individual protein's effect size is modest, when combined together, a much larger effect can be achieved. Finally, our subgroup analyses by histologic subtype are limited by small numbers of cases, especially for non-endometrioid carcinoma, and we were not able to assess the associations for a more detailed classification of EC. Future studies with improved statistical power are needed to better investigate the associations for this more aggressive and specific type of EC.

\section{Conclusions}

In summary, in this large study using genetic variants as instruments, we identified nine protein biomarkers with their genetically predicted circulating concentrations associated with EC risk. Our study provided a list of EC-associated protein biomarkers, which, if validated in additional studies, will not only contribute to the understanding of endometrial tumorigenesis but also facilitate risk assessment of EC combined with other findings.

Author Contributions: Conceptualization: J.Z., L.W. and H.Y.; data collection: V.W.S., D.G., A.B.S., P.A.F., D.L. (Diether Lambrechts), D.B., L.S.C., C.F., J.V.L., C.C., N.W., I.D.V., M.D., X.-O.S., W.Z.; data analysis: J.Z., T.A.O., D.L. (Duo Liu), manuscript writing: J.Z.; manuscript revision: J.Z., T.A.O., D.L. (Duo Liu), V.W.S., D.G., A.B.S., P.A.F., D.L. (Diether Lambrechts), D.B., P.F.K., L.S.C., C.F., J.V.L., C.C., N.W., I.D.V., Y.S., J.L., M.D., X.-O.S., W.Z., L.W., H.Y. All authors have read and agreed to the published version of the manuscript.

Funding: This research received no external funding.

Institutional Review Board Statement: This study has been approved by the Institutional Review Board of the University of Hawaii (IRB2019-00402).

Informed Consent Statement: Informed consent was obtained from all subjects involved in the study.

Data Availability Statement: The data that support the findings of this study are available from the corresponding author upon reasonable request.

Acknowledgments: We thank the many individuals who participated in the parent studies as part of $\mathrm{ECAC}$ and $\mathrm{E} 2 \mathrm{C} 2$ consortia and the numerous institutions and their staff who supported recruitment. The iCOGS and OncoArray endometrial cancer analysis were supported by NHMRC project grants (ID\#1031333 and ID\#1109286) to A.B.S., D.F.E., A.M.D., D.J.T. and I.T., A.B.S. (APP1061779), P.M.W. and T.A.O. (APP1111246) are supported by the NHMRC Fellowship scheme. A.M.D. was supported by the Joseph Mitchell Trust. I.T. is supported by Cancer Research UK and the Oxford Comprehensive Biomedical Research Center. Funding for the iCOGS infrastructure came from: the European Community's Seventh Framework Programme under grant agreement no. 223175 (HEALTH-F2-2009-223175) (COGS), Cancer Research UK (C1287/A10118, C1287/A10710, C12292/A11174, C1281/A12014, C5047/A8384, C5047/A15007, C5047/A10692, C8197/A16565), the National Institutes of Health (CA128978) and Post-Cancer GWAS initiative (1U19 CA148537, 1U19 CA148065 and 1U19 CA148112the GAME-ON initiative), the Department of Defence (W81XWH-10-1-0341), the Canadian Institutes of Health Research (CIHR) for the CIHR Team in Familial Risks of Breast Cancer, Komen Foundation 
for the Cure, the Breast Cancer Research Foundation, and the Ovarian Cancer Research Fund. OncoArray genotyping of ECAC cases was performed with the generous assistance of the Ovarian Cancer Association Consortium (OCAC). The OCAC OncoArray genotyping project was funded through grants from the US National Institutes of Health (CA1X01HG007491-01 (Christopher I. Amos), U19CA148112 (Thomas A. Sellers), R01-CA149429 (Catherine M. Phelan), and R01-CA058598 (Marc T. Goodman)); Canadian Institutes of Health Research (MOP-86727 (Linda E. Kelemen)); and the Ovarian Cancer Research Fund (Andrew Berchuck). CIDR genotyping for the Oncoarray was conducted under contract 268201200008I. OncoArray genotyping of the BCAC controls was funded by Genome Canada Grant GPH-129344, NIH Grant U19 CA148065, and Cancer UK Grant C1287/A16563. ANECS recruitment was supported by project grants from the NHMRC (ID\#339435), The Cancer Council Queensland (ID\#4196615), and Cancer Council Tasmania (ID\#403031 and ID\#457636). SEARCH recruitment was funded by a program grant from Cancer Research UK (C490/A10124). Stage 1 and stage 2 case genotyping was supported by the NHMRC (ID\#552402, ID\#1031333). Control data were generated by the Wellcome Trust Case Control Consortium (WTCCC), and a full list of the investigators who contributed to the generation of the data is available from the WTCCC website. We acknowledge use of DNA from the British 1958 Birth Cohort collection, funded by the Medical Research Council grant G0000934 and the Wellcome Trust grant 068545/Z/02_funding for this project was provided by the Wellcome Trust under award 085475. NSECG was supported by the EU FP7 CHIBCHA grant, Wellcome Trust Centre for Human Genetics Core Grant 090532/Z/09Z, and CORGI was funded by Cancer Research UK. We thank Nick Martin, Dale Nyholt, and Anjali Henders for access to GWAS data from QIMR Controls. Recruitment of the QIMR controls was supported by the NHMRC. The University of Newcastle, the Gladys M Brawn Senior Research Fellowship scheme, The Vincent Fairfax Family Foundation, the Hunter Medical Research Institute, and the Hunter Area Pathology Service all contributed toward the costs of establishing the Hunter Community Study. The Bavarian Endometrial Cancer Study (BECS) was partly funded by the ELAN fund of the University of Erlangen. The Hannover-Jena Endometrial Cancer Study was partly supported by the Rudolf Bartling Foundation. The Leuven Endometrium Study (LES) was supported by the Verelst Foundation for endometrial cancer. The Mayo Endometrial Cancer Study (MECS) and Mayo controls (MAY) were supported by grants from the National Cancer Institute of United States Public Health Service (R01 CA122443, P30 CA15083, P50 CA136393, and GAME-ON the NCI Cancer Post-GWAS Initiative U19 CA148112), the Fred C and Katherine B Andersen Foundation, the Mayo Foundation, and the Ovarian Cancer Research Fund with support of the Smith family, in memory of Kathryn Sladek Smith. MoMaTEC received financial support from a Helse Vest Grant, the University of Bergen, Melzer Foundation, The Norwegian Cancer Society (Harald Andersens legat), The Research Council of Norway and Haukeland University Hospital. The Newcastle Endometrial Cancer Study (NECS) acknowledges contributions from the University of Newcastle, The NBN Children's Cancer Research Group, Jennie Thomas, and the Hunter Medical Research Institute. RENDOCAS was supported through the regional agreement on medical training and clinical research (ALF) between Stockholm County Council and Karolinska Institutet (numbers: 20110222, 20110483, 20110141 and DF07015), The Swedish Labor Market Insurance (number 100069), and The Swedish Cancer Society (number 11 0439). The Cancer Hormone Replacement Epidemiology in Sweden Study (CAHRES, formerly named The Singapore and Swedish Breast/Endometrial Cancer Study; SASBAC) was supported by funding from the Agency for Science, Technology and Research of Singapore (A*STAR), the US National Institutes of Health, and the Susan G. Komen Breast Cancer Foundation. The WHI program is funded by the National Heart, Lung, and Blood Institute, the US National Institutes of Health, and the US Department of Health and Human Services (HHSN268201100046C, HHSN268201100001C, HHSN268201100002C, HHSN268201100003C, HHSN268201100004C, and HHSN271201100004C). This work was also funded by NCI U19 CA148065-01. The Nurses' Health Study (NHS) is supported by the NCI, NIH Grants Number UM1 CA186107, P01 CA087969, R01 CA49449, 1R01 CA134958, and 2R01 CA082838. We thank the participants and staff of the Nurses' Health Study for their valuable contributions as well as the following state cancer registries for their help: A.L., A.Z., A.R., C.A., C.O., C.T., D.E., F.L., G.A., I.D., I.L., I.N., I.A., K.Y., L.A., M.E., M.D., M.A., M.I., N.E., N.H., N.J., N.Y., N.C., N.D., O.H., O.K., O.R., P.A., R.I., S.C., T.N., T.X., V.A., W.A. and W.Y. We assume full responsibility for the analyses and interpretation of these data. We also thank Channing Division of Network Medicine, Department of Medicine, Brigham and Women's Hospital, and Harvard Medical School. Finally, we also acknowledge Pati Soule and Hardeep Ranu for their laboratory assistance. The Connecticut Endometrial Cancer Study was supported by NCI, NIH Grant Number RO1CA98346. The Fred Hutchinson Cancer Research Center (FHCRC) is supported by NCI, NIH 
Grant Number NIH RO1 CA105212, RO1 CA 87538, RO1 CA75977, RO3 CA80636, NO1 HD23166, R35 CA39779, KO5 CA92002, and funds from the Fred Hutchinson Cancer Research Center. The Multiethnic Cohort Study (MEC) is supported by the NCI, NHI Grants Number CA54281, CA128008, and 2R01 CA082838. The California Teachers Study (CTS) is supported by NCI, NIH Grant Number 2R01 CA082838, R01 CA91019, and R01 CA77398, and contract 97-10500 from the California Breast Cancer Research Fund. The Polish Endometrial Cancer Study (PECS) is supported by the Intramural Research Program of the NCI. The Prostate, Lung, Colorectal, and Ovarian Cancer Screening Trial (PLCO) is supported by the Extramural and the Intramural Research Programs of the NCI. The WHI program is funded by the National Heart, Lung, and Blood Institute, National Institutes of Health, U.S. Department of Health and Human Services through contracts, HHSN268201600018C, HHSN268201600001C, HHSN268201600002C, HHSN268201600003C, and HHSN268201600004C. The Breast Cancer Association Consortium (BCAC) is funded by Cancer Research UK (C1287/A10118, C1287/A12014). The Ovarian Cancer Association Consortium (OCAC) is supported by a grant from the Ovarian Cancer Research Fund thanks to donations by the family and friends of Kathryn Sladek Smith (PPD/RPCI.07), and the UK National Institute for Health Research Biomedical Research Centres at the University of Cambridge.

Conflicts of Interest: The authors declare no conflict of interest.

\section{References}

1. Braun, M.M.; Overbeek-Wager, E.A.; Grumbo, R.J. Diagnosis and Management of Endometrial Cancer. Am. Fam. Physician 2016, 93, 468-474. [PubMed]

2. Onstad, M.A.; Schmandt, R.E.; Lu, K.H. Addressing the Role of Obesity in Endometrial Cancer Risk, Prevention, and Treatment. J. Clin. Oncol. Off. J. Am. Soc. Clin. Oncol. 2016, 34, 4225-4230. [CrossRef]

3. Ray-Coquard, I.; Favier, L.; Weber, B.; Roemer-Becuwe, C.; Bougnoux, P.; Fabbro, M.; Floquet, A.; Joly, F.; Plantade, A.; Paraiso, D.; et al. Everolimus as Second- or Third-Line Treatment of Advanced Endometrial Cancer: ENDORAD, a Phase II Trial of GINECO. Br. J. Cancer 2013, 108, 1771-1777. [CrossRef] [PubMed]

4. Hutt, S.; Tailor, A.; Ellis, P.; Michael, A.; Butler-Manuel, S.; Chatterjee, J. The Role of Biomarkers in Endometrial Cancer and Hyperplasia: A Literature Review. Acta Oncol. Stockh. Swed. 2019, 58, 342-352. [CrossRef] [PubMed]

5. Bagaria, M.; Shields, E.; Bakkum-Gamez, J.N. Novel Approaches to Early Detection of Endometrial Cancer. Curr. Opin. Obstet. Gynecol. 2017, 29, 40-46. [CrossRef] [PubMed]

6. Rižner, T.L. Discovery of Biomarkers for Endometrial Cancer: Current Status and Prospects. Expert Rev. Mol. Diagn. 2016, 16, 1315-1336. [CrossRef]

7. Njoku, K.; Chiasserini, D.; Whetton, A.D.; Crosbie, E.J. Proteomic Biomarkers for the Detection of Endometrial Cancer. Cancers 2019, 11, 1572. [CrossRef]

8. Panici, P.B.; Scambia, G.; Baiocchi, G.; Perrone, L.; Greggi, S.; Battaglia, F.; Mancuso, S. Multiple Serum Markers in Patients with Endometrial Cancer. Gynecol. Obstet. Investig. 1989, 27, 208-212. [CrossRef]

9. Scambia, G.; Gadducci, A.; Panici, P.B.; Foti, E.; Ferdeghini, M.; Ferrandina, G.; Amoroso, M.; Castellani, C.; Facchini, V.; Mancuso, S. Combined Use of CA 125 and CA 15-3 in Patients with Endometrial Carcinoma. Gynecol. Oncol. 1994, 54, 292-297. [CrossRef]

10. Kanat-Pektas, M.; Yenicesu, O.; Gungor, T.; Bilge, U. Predictive Power of Sexual Hormones and Tumor Markers in Endometrial Cancer. Arch. Gynecol. Obstet. 2010, 281, 709-715. [CrossRef]

11. Wang, Y.; Cao, R.; Jin, H.; Huang, Y.; Zhang, X.; Cong, Q.; He, Y.; Xu, C. Altered Protein Expression in Serum from Endometrial Hyperplasia and Carcinoma Patients. J. Hematol. Oncol. 2011, 4, 15. [CrossRef] [PubMed]

12. Cocco, E.; Bellone, S.; El-Sahwi, K.; Cargnelutti, M.; Buza, N.; Tavassoli, F.A.; Schwartz, P.E.; Rutherford, T.J.; Pecorelli, S.; Santin, A.D. Serum Amyloid A: A Novel Biomarker for Endometrial Cancer. Cancer 2010, 116, 843-851. [CrossRef]

13. Omer, B.; Genc, S.; Takmaz, O.; Dirican, A.; Kusku-Kiraz, Z.; Berkman, S.; Gurdol, F. The Diagnostic Role of Human Epididymis Protein 4 and Serum Amyloid-A in Early-Stage Endometrial Cancer Patients. Tumour Biol. 2013, 34, 2645-2650. [CrossRef]

14. Tarney, C.M.; Wang, G.; Bateman, N.W.; Conrads, K.A.; Zhou, M.; Hood, B.L.; Loffredo, J.; Tian, C.; Darcy, K.M.; Hamilton, C.A.; et al. Biomarker Panel for Early Detection of Endometrial Cancer in the Prostate, Lung, Colorectal, and Ovarian Cancer Screening Trial. Am. J. Obstet. Gynecol. 2019, 221, 472.e1-472.e10. [CrossRef]

15. Zhu, J.; Shu, X.; Guo, X.; Liu, D.; Bao, J.; Milne, R.L.; Giles, G.G.; Wu, C.; Du, M.; White, E.; et al. Associations between Genetically Predicted Blood Protein Biomarkers and Pancreatic Cancer Risk. Cancer Epidemiol. Biomark. 2020, 29, 1501-1508. [CrossRef]

16. Sun, B.B.; Maranville, J.C.; Peters, J.E.; Stacey, D.; Staley, J.R.; Blackshaw, J.; Burgess, S.; Jiang, T.; Paige, E.; Surendran, P.; et al. Genomic Atlas of the Human Plasma Proteome. Nature 2018, 558, 73-79. [CrossRef]

17. O'Mara, T.A.; Glubb, D.M.; Amant, F.; Annibali, D.; Ashton, K.; Attia, J.; Auer, P.L.; Beckmann, M.W.; Black, A.; Bolla, M.K.; et al. Identification of Nine New Susceptibility Loci for Endometrial Cancer. Nat. Commun. 2018, 9, 3166. [CrossRef]

18. Burgess, S.; Butterworth, A.; Thompson, S.G. Mendelian Randomization Analysis with Multiple Genetic Variants Using Summarized Data. Genet. Epidemiol. 2013, 37, 658-665. [CrossRef] 
19. Wu, L.; Shu, X.; Bao, J.; Guo, X.; Kote-Jarai, Z.; Haiman, C.A.; Eeles, R.A.; Zheng, W. PRACTICAL, CRUK, BPC3, CAPS, PEGASUS Consortia Analysis of Over 140,000 European Descendants Identifies Genetically Predicted Blood Protein Biomarkers Associated with Prostate Cancer Risk. Cancer Res. 2019, 79, 4592-4598. [CrossRef] [PubMed]

20. Shu, X.; Bao, J.; Wu, L.; Long, J.; Shu, X.-O.; Guo, X.; Yang, Y.; Michailidou, K.; Bolla, M.K.; Wang, Q.; et al. Evaluation of Associations between Genetically Predicted Circulating Protein Biomarkers and Breast Cancer Risk. Int. J. Cancer 2020, 146, 2130-2138. [CrossRef] [PubMed]

21. Krämer, A.; Green, J.; Pollard, J.; Tugendreich, S. Causal Analysis Approaches in Ingenuity Pathway Analysis. Bioinforma. Oxf. Engl. 2014, 30, 523-530. [CrossRef]

22. Lim, D.; Oliva, E. Nonendometrioid Endometrial Carcinomas. Semin. Diagn. Pathol. 2010, 27, 241-260. [CrossRef] [PubMed]

23. Martinez-Garcia, E.; Lopez-Gil, C.; Campoy, I.; Vallve, J.; Coll, E.; Cabrera, S.; Ramon, Y.; Cajal, S.; Matias-Guiu, X.; Van Oostrum, J.; et al. Advances in Endometrial Cancer Protein Biomarkers for Use in the Clinic. Expert Rev. Proteom. 2018, 15, 81-99. [CrossRef]

24. Chrysovergis, K.; Wang, X.; Kosak, J.; Lee, S.-H.; Kim, J.S.; Foley, J.F.; Travlos, G.; Singh, S.; Baek, S.J.; Eling, T.E. NAG-1/GDF-15 Prevents Obesity by Increasing Thermogenesis, Lipolysis and Oxidative Metabolism. Int. J. Obes. 2014, 38, 1555-1564. [CrossRef] [PubMed]

25. Kyrgios, I.; Galli-Tsinopoulou, A.; Stylianou, C.; Papakonstantinou, E.; Arvanitidou, M.; Haidich, A.-B. Elevated Circulating Levels of the Serum Acute-Phase Protein YKL-40 (Chitinase 3-like Protein 1) Are a Marker of Obesity and Insulin Resistance in Prepubertal Children. Metabolism 2012, 61, 562-568. [CrossRef] [PubMed]

26. Hempen, M.; Kopp, H.-P.; Elhenicky, M.; Höbaus, C.; Brix, J.-M.; Koppensteiner, R.; Schernthaner, G.; Schernthaner, G.-H. YKL-40 Is Elevated in Morbidly Obese Patients and Declines after Weight Loss. Obes. Surg. 2009, 19, 1557-1563. [CrossRef]

27. Shaw, E.; Farris, M.; McNeil, J.; Friedenreich, C. Obesity and Endometrial Cancer. Recent Results Cancer Res. 2016, 208, 107-136. [CrossRef] [PubMed]

28. O'Mara, T.A.; Spurdle, A.B.; Glubb, D.M. Endometrial Cancer Association Consortium Endometrial Cancer Association Consortium Analysis of Promoter-Associated Chromatin Interactions Reveals Biologically Relevant Candidate Target Genes at Endometrial Cancer Risk Loci. Cancers 2019, 11, 1440. [CrossRef] [PubMed]

29. Fitau, J.; Boulday, G.; Coulon, F.; Quillard, T.; Charreau, B. The Adaptor Molecule Lnk Negatively Regulates Tumor Necrosis Factor-Alpha-Dependent VCAM-1 Expression in Endothelial Cells through Inhibition of the ERK1 and -2 Pathways. J. Biol. Chem. 2006, 281, 20148-20159. [CrossRef]

30. Kullo, I.J.; Shameer, K.; Jouni, H.; Lesnick, T.G.; Pathak, J.; Chute, C.G.; de Andrade, M. The ATXN2-SH2B3 Locus Is Associated with Peripheral Arterial Disease: An Electronic Medical Record-Based Genome-Wide Association Study. Front. Genet. 2014, 5, 166. [CrossRef] [PubMed]

31. Romanowicz-Makowska, H.; Smolarz, B.; Połać, I.; Sporny, S. Single Nucleotide Polymorphisms of RAD51 G135C, XRCC2 Arg188His and XRCC3 Thr241Met Homologous Recombination Repair Genes and the Risk of Sporadic Endometrial Cancer in Polish Women: Polymorphism of RAD51, XRCC2 and XRCC3 and Endometrial Cancer. J. Obstet. Gynaecol. Res. 2012, 38, 918-924. [CrossRef]

32. Michalska, M.M.; Samulak, D.; Romanowicz, H.; Smolarz, B. Association of Polymorphisms in the 5' Untranslated Region of RAD51 Gene with Risk of Endometrial Cancer in the Polish Population. Arch. Gynecol. Obstet. 2014, 290, 985-991. [CrossRef]

33. Krupa, R.; Sobczuk, A.; Popławski, T.; Wozniak, K.; Blasiak, J. DNA Damage and Repair in Endometrial Cancer in Correlation with the HOGG1 and RAD51 Genes Polymorphism. Mol. Biol. Rep. 2011, 38, 1163-1170. [CrossRef]

34. Tsukazaki, K.; Sakayori, M.; Arai, H.; Yamaoka, K.; Kurihara, S.; Nozawa, S. Abnormal Expression of Blood Group-Related Antigens in Uterine Endometrial Cancers. Jpn. J. Cancer Res. GANN 1991, 82, 934-941. [CrossRef]

35. Xu, W.-H.; Zheng, W.; Xiang, Y.-B.; Shu, X.-O. ABO Blood Type Is Associated with Endometrial Cancer Risk in Chinese Women. Chin. J. Cancer 2011, 30, 766-771. [CrossRef] [PubMed]

36. Yuzhalin, A.E.; Kutikhin, A.G. ABO and Rh Blood Groups in Relation to Ovarian, Endometrial and Cervical Cancer Risk among the Population of South-East Siberia. Asian Pac. J. Cancer Prev. APJCP 2012, 13, 5091-5096. [CrossRef] [PubMed]

37. Abu-Zaid, A.; Alsabban, M.; Abuzaid, M.; Alomar, O.; Al-Badawi, I.A.; Salem, H. ABO Blood Group and Endometrial Carcinoma: A Preliminary Single-Center Experience from Saudi Arabia. Cureus 2017, 9, e1959. [CrossRef] [PubMed]

38. Schlosser, P.; Li, Y.; Sekula, P.; Raffler, J.; Grundner-Culemann, F.; Pietzner, M.; Cheng, Y.; Wuttke, M.; Steinbrenner, I.; Schultheiss, U.T.; et al. Genetic Studies of Urinary Metabolites Illuminate Mechanisms of Detoxification and Excretion in Humans. Nat. Genet. 2020, 52, 167-176. [CrossRef]

39. Kim, S.K. Identification of 613 New Loci Associated with Heel Bone Mineral Density and a Polygenic Risk Score for Bone Mineral Density, Osteoporosis and Fracture. PLoS ONE 2018, 13, e0200785. [CrossRef]

40. Kichaev, G.; Bhatia, G.; Loh, P.-R.; Gazal, S.; Burch, K.; Freund, M.K.; Schoech, A.; Pasaniuc, B.; Price, A.L. Leveraging Polygenic Functional Enrichment to Improve GWAS Power. Am. J. Hum. Genet. 2019, 104, 65-75. [CrossRef] [PubMed]

41. Warrington, N.M.; Beaumont, R.N.; Horikoshi, M.; Day, F.R.; Helgeland, Ø.; Laurin, C.; Bacelis, J.; Peng, S.; Hao, K.; Feenstra, B.; et al. Maternal and Fetal Genetic Effects on Birth Weight and Their Relevance to Cardio-Metabolic Risk Factors. Nat. Genet. 2019, 51, 804-814. [CrossRef] [PubMed] 